\title{
Use of an interdisciplinary, participatory design approach to develop a usable patient self-assessment tool in atrial fibrillation
}

This article was published in the following Dove Press journal:

Patient Preference and Adherence

4 November 2013

Number of times this article has been viewed

\author{
Lori MacCallum ${ }^{1,2}$ \\ Heather McGaw' \\ Nazanin Meshkat ${ }^{3}$ \\ Alissia Valentinis ${ }^{4}$ \\ Leslie Beard Ashley ${ }^{5}$ \\ Rajan Sacha Bhatia ${ }^{3,6,7}$ \\ Kaye Benson ${ }^{7}$ \\ Noah Ivers ${ }^{6,8}$ \\ Kori Leblanc 2,7 \\ Dante Morra ${ }^{3,5,7}$
}

'Li Ka Shing Knowledge Institute, St Michael's Hospital, Toronto, ${ }^{2}$ Leslie Dan Faculty of Pharmacy, University of Toronto, ${ }^{3}$ Department of Medicine, University of Toronto, Toronto, ${ }^{4}$ Taddle Creek Family Health Team, Toronto, ${ }^{5}$ Trillium Health Partners, Mississauga, ${ }^{6}$ Women's College Hospital, Toronto, ${ }^{7}$ Centre for Innovation in Complex Care, University Health Network, Toronto, ${ }^{8}$ Department of Family and Community Medicine, University of Toronto, Toronto, ON, Canada

\section{Video abstract}

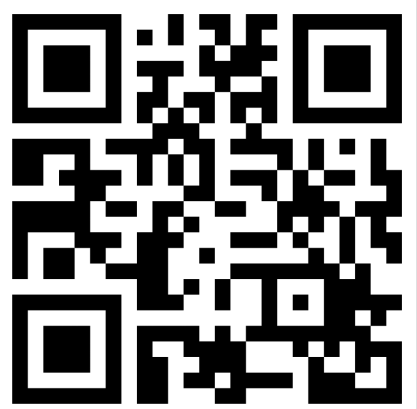

Point your SmartPhone at the code above. If you have a QR code reader the video abstract will appear. Or use: http://dvpr.es/IdKIDd]

Correspondence: Lori MacCallum Banting and Best Diabetes Centre, Faculty of Medicine, University of Toronto, 200 Elizabeth St Eaton Building, I2E252, ON M5G 2C4, Canada

Tel +I 4 I 63404800 ext 2784

Fax + I 4169784108

Email lori.maccallum@uhnresearch.ca
Abstract: After identifying that significant care gaps exist within the management of atrial fibrillation (AF), a patient-focused tool was developed to help patients better assess and manage their AF. This tool aims to provide education and awareness regarding the management of symptoms and stroke risk associated with AF, while engaging patients to identify if their condition is optimally managed and to become involved in their own care. An interdisciplinary group of health care providers and designers worked together in a participatory design approach to develop the tool with input from patients. Usability testing was completed with 22 patients of varying demographics to represent the characteristics of the patient population. The findings from usability testing interviews were used to further improve and develop the tool to improve ease of use. A physician-facing tool was also developed to help to explain the tool and provide a brief summary of the 2012 Canadian Cardiovascular Society atrial fibrillation guidelines. By incorporating patient input and human-centered design with the knowledge, experience, and medical expertise of health care providers, we have used an approach in developing the tool that tries to more effectively meet patients' needs.

Keywords: patient education, atrial fibrillation, care gaps, patient care tools, patient self-assessment

\section{Background}

Atrial fibrillation (AF), is the most common heart rhythm disorder, and primarily affects the elderly. ${ }^{1,2}$ AF causes significant morbidity and mortality and is a significant driver of emergency room visits and hospitalizations. ${ }^{3,4}$

Cardioembolism due to AF accounts for approximately one in six ischemic strokes (one in four in the elderly) and is a cause of stroke-related disability, dementia, and death. $^{5}$ At least $60 \%$ of patients who have a stroke will end up with some form of permanent disability. ${ }^{5}$ In addition, patients with AF experience symptoms, including palpitations, shortness of breath, light-headedness, dizziness, and/or chest pain, which can be extremely bothersome and greatly impact their quality of life. ${ }^{6}$ Often these symptoms lead to unplanned visits to the primary care provider and unnecessary emergency room visits. ${ }^{3}$

Fortunately, much of the morbidity and mortality associated with AF is preventable with appropriate therapy, such as treatment with anticoagulation and the use of medications that control heart rate and/or rhythm. ${ }^{2,7,8}$ However, in a Canadian registry study of patients with AF admitted with a first ischemic stroke and who were candidates for anticoagulation, most were not taking anticoagulation $(60 \%)$. In addition, 39\% taking anticoagulation were sub-therapeutic at the time of ischemic stroke. ${ }^{5}$ 
Patient education on management of symptoms and stroke risk is needed. New approaches to chronic disease management have stressed the importance of more informed and 'activated' patients who are given sufficient tools to comanage their health with their health care team. 'Activated' patients rank high on self-efficacy scales, a proxy measure for confidence in managing their illness, for example, their perceived ability to navigate the health care system, follow medical advice, manage symptoms, and maintain their physical and emotional well-being. 10 'Activated' patients do better on a range of health outcomes and, by being better self-managers, can improve health system efficiency. ${ }^{11,12}$ For example, research suggests that these patients have better relationships with their health care providers, have fewer hospitalizations, and have improved understanding of and compliance with recommended treatment regimes. ${ }^{13,14}$

Establishing interdisciplinary teams composed of health care providers, designers, and patients may be an effective way to develop tools that both engage patients and better meet their needs. Health care providers have expertise on disease states and their management but also have an intimate knowledge of the care gaps that exist for their patients. Designers, especially those with expertise in human-centered design, focus primarily on the needs of the end user and how they will use the tool in their daily life to make it compelling and meaningful. Finally, patient input is critical to test assumptions and ensure ease of use and understanding. This approach enables teams to develop, test, and iterate on the tool quickly, with pain points identified early on.

\section{Methods/change process}

An interdisciplinary, participatory design approach was used to develop a patient-facing tool targeted at patients with AF. As part of a larger project aiming to develop a new care model to improve the care of patients with AF, a group of clinicians, designers, and researchers from the Health Design Lab at Li Ka Shing Knowledge Institute, St Michael's Hospital and the Centre for Innovation in Complex Care at the University Health Network, Toronto, Canada, set out to develop this AF patient-facing tool. The principle behind this tool is to allow patients to determine if their management is optimal according to the 2012 Canadian Cardiovascular Society (CCS) AF guidelines, ${ }^{15}$ and if not, to empower them to speak to their primary care provider.

\section{Preparatory work}

The team conducted stakeholder interviews across the spectrum of AF care and reviewed both the medical literature and the existing tools on the Internet. Five key gap areas were identified: patient understanding of AF; symptom management; rate versus rhythm control versus electrocardioversion; anticoagulation; and stroke prevention. These care gaps were then used as a starting point when the team met for a brainstorming session to discuss how significant care gaps that exist in the management of AF could be addressed.

Given the potential benefits of preventing disability and death related to stroke, as well as avoiding the need for acute emergency care, the team decided to focus the tool on stroke prevention and symptom management. Following the brainstorming session, the generated ideas were mapped out according to themes, and presented back to the participants to confirm the direction that would be taken in terms of target audience, key messages, and type of tool to be developed.

\section{Tool design and development}

The tool was developed using an iterative process, with 33 versions created, each of which was cycled back through the clinical and design teams with input from stakeholders and end users. Clinical content was developed by an interdisciplinary group of clinicians, including pharmacists, nurses, nurse practitioners, cardiologists, general internists, emergency room physicians, and primary care providers. The tool design was created by designers with expertise in human-centered design. Both groups met separately as well as jointly on a weekly basis to ensure the clinical content and design were optimized and complementary.

\section{Usability testing}

Usability testing was completed with an early version of the quiz (see Figures 1 and 2) with 22 patients of various ages from different primary care and cardiology clinics to represent our end-user demographic. Testing was completed using a standardized script and questions developed by both clinicians and designers (see the Supplementary material). A user experience designer then trained a clinician to complete the usability testing interviews with patients. Data from interviews were compiled and analyzed by a user experience designer according to consequence, recoverability, frequency of occurrence, and rational cause. ${ }^{16}$ Findings were then used to improve upon the tool.

\section{Results}

\section{Findings from usability testing and changes made}

\section{Finding I: information was too general}

Most users believed that 'Know Your Colours' was providing them with basic information about AF and the heart. Very few 


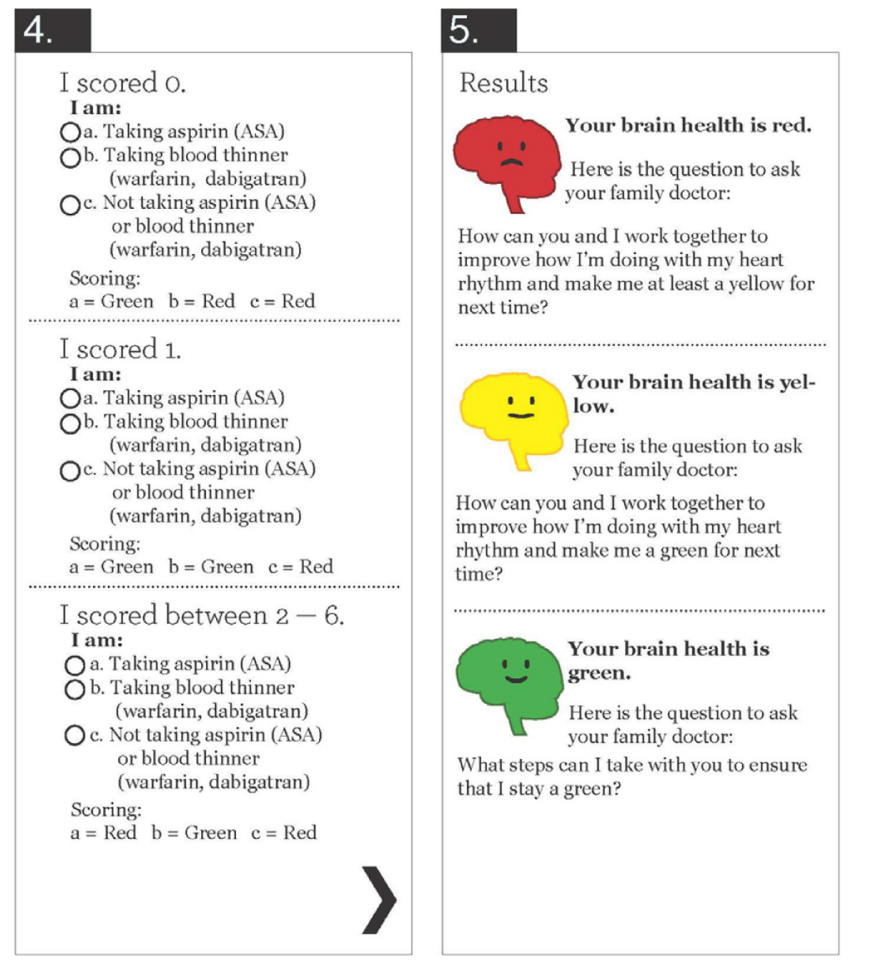

\section{Do You Know Your Atrial Fibrillation Colours?}

What is atrial fibrillation?

Atrial fibrillation is an electrical disturbance of the heart where the heart is beating irregularly and fast. This can affect your heart and brain

\section{Why should I care?}

Atrial Fibrillation increases your risk of stroke (a clot in the brain). It can also af fect your quality of life because many of the symptoms are uncomfortable. However, it's possible you may not feel any symptoms.

What can be done?

There are a variety of treatments and options available that can improve you health and reduce your symptoms and risk of stroke.

By going through the following quiz and identifying your colour, you will know what to ask your heal th care team to ensure that you are receiving the best treatment for you.

Figure I Initial version, patient-facing tool for stroke risk assessment.

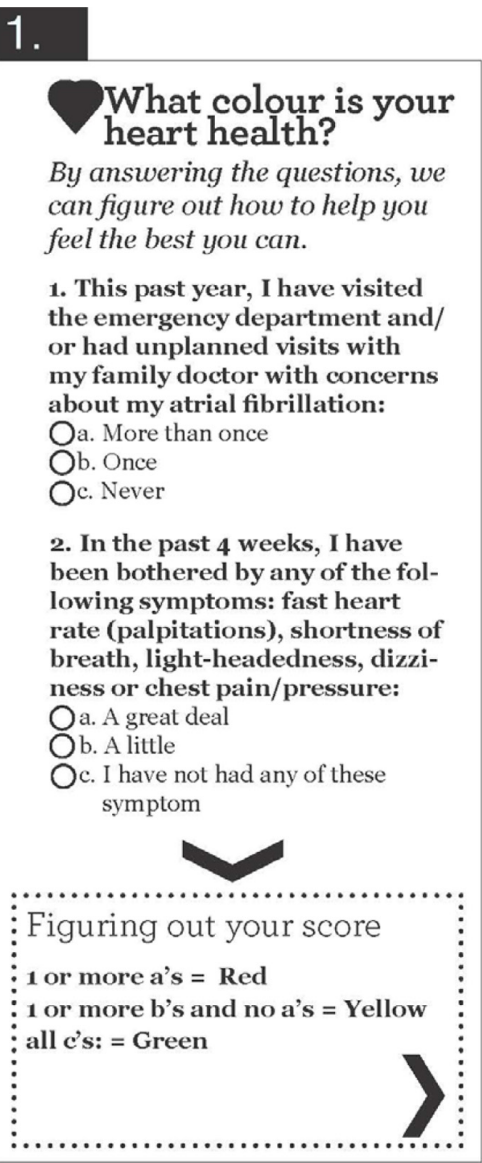

\section{2.}

Results

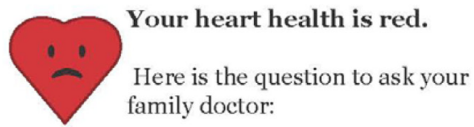

How can you and I work together to improve how I'm doing with my heart rhythm and make me at least a yellow for next time?

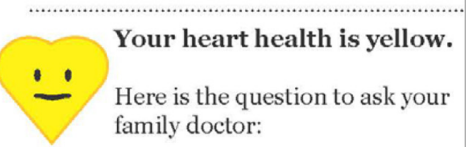

How can you and I work together to improve how I'm doing with my heart rhythm and make me a green for next time?

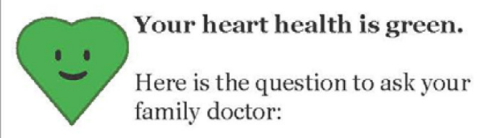

What steps can I take with you to ensure that I stay a green?

\section{What colour is your brain health?}

By answering the questions, we can figure out how to help prevent you from having a stroke.

\section{3}

1. I have congestive heart failure. Oa. Yes (1 point)

Ob. No

Oc. I don't know

2. I have high blood pressure or am taking blood pressure medication(s). Oa. Yes (1 point)

Ob. No

Oc. I don't know

3. I am 75 years of age or older. Oa. Yes (1 point)

Ob. No

4. I have diabetes.

Oa. Yes (1 point)

Ob. No

Oc. I don't know

5. I have previously had a stroke or mini-stroke (Transient Ischemic Attack or TIA).

O. Yes (2 points)

Ob. No

c. I don't know

Figuring out your score

If you answered 'I don't know' to

any of the previous questions please

take this sheet to your family doctor

and ask them to help you complete

the quiz.

Please write your score here and continue:

Figure 2 Initial version, patient-facing tool for symptom management. 
participants expressed that they thought this was primarily an assessment tool.

Action: We focused on the purpose of tool, removed "What is atrial fibrillation?", "Why should I care?", and "What can be done?" and refocused the introductory content on explaining the concept and tool.

\section{Finding 2: participants were not confident} that their physician would know what the material was or what to do with it

Action: We addressed this by developing a physician-facing tool that would accompany the patient-facing tool.

\section{Finding 3: there was confusion about what} the colors meant

Action: The legend for the heart and brain colors was made consistently visible throughout the quiz sections.

\section{Finding 4: participants had trouble figuring out their score}

They were missing the scoring at the bottom and moving forward prematurely.

Action: The format of the tool was changed so that parts 1 and 2 were confined to their own respective pages. Therefore, participants could complete the quiz and score without having to move to a different page or section of the page.

\section{Finding 5: lack of direction in what to do with the results}

"You showed me a red so it doesn't look good for me, but how bad is it?"

Action: Information in the results section was changed to give more direction to the patient, including how soon they should follow up with their family doctor.

\section{Finding 6: participants were not clear on what was} brain health and what was heart health content

There was too much flipping back and forth between pages, and participants had trouble following the arrows. Positioning of brain health results on the back was problematic because participants were not turning to the back and referred instead to the heart health results, which caused confusion.

Action: The format of the tool was redesigned from a brochure format to a booklet format to create a more linear path through the self-assessment.

\section{Finding 7: scoring was difficult}

Participants had trouble adding up points and sometimes did not see them.
Action: Scoring was completely redesigned so that determining the score required minimal work on the patients' part.

\section{Finding 8: many participants did not know what the term 'congestive heart failure' meant}

Action: The language in the question was changed from "I have congestive heart failure." to "I have heart failure or I have been told I have water in the lungs."

The final 'Know Your Colours' tool has evolved into an educational program for patients and providers. It includes a self-assessment and educational tool for patients with AF designed to capture information on stroke risk, impact of symptoms on daily living, unplanned visits to their primary care provider and emergency room visits (see Figure 3). Appropriateness of management is based on the 2012 CCS AF guidelines. ${ }^{15}$ Symptom management, referred to as 'Heart Health', and stroke management, referred to as 'Brain Health', are scored separately. Based on the responses, patients are classified as 'green', 'yellow', or 'red', with specific instructions on how soon to follow up with their primary care provider based on their result.

The accompanying letter to the primary care provider comprises a description of the 'Know Your Colours' program and its importance on the front page, with a tool to aid clinicians in the management of AF on the back page. It includes information on diagnosis, medication management, and monitoring and is adapted from the Canadian Cardiovascular Pharmacists Network Stroke Prevention in AF Pocket Reference (www. ccpn.ca) and the 2012 CCS AF guidelines ${ }^{15}$ (see Figure 4).

\section{Discussion}

'Know Your Colours' was designed to allow patients to use it easily and enable them to better understand AF and, help them assess whether they are being optimally managed based on their risk of stroke and general symptoms. Through increasing patient understanding of AF symptoms and management, the end goal will be to empower patients to self-assess their condition and consult with their primary health care provider if they are being sub-optimally managed or have additional questions.

Through our team's interdisciplinary and patient-inclusive approach, we were able to design a tool that incorporated many different perspectives and areas of expertise, including those of the patients themselves. Traditionally, clinicians working in a given therapeutic area develop patient education tools based on what they think is important for the patient to know. It may then be reviewed by a Patient Education 
More information available at: www.knowyourcolours.com

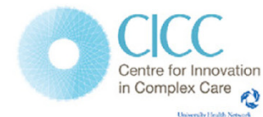

St. Michael's Health Design Lab
Atrial

Fibrillation

\section{Do you know your colours?}

Know Your Colours is a quiz (two short ones actually) for people with atrial fibrillation. Two important goals in the management of your atrial fibrillation are:

1. reducing your risk of having a stroke (Brain Health)

2. control of your symptoms (Heart Health)

Complete this quiz to find out how well these are being managed. Your doctor wants to im prove your care and this quiz can be used as a conversation starter to help you to get and stay on track.

St. Michael's

Health Design Lab

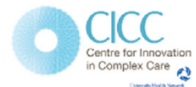

\section{Find your heart health colour}

Step 1 1. In the past 4 weeks one or more of the following heart symptoms have bothered me: fast heart rate, heart skipping a beat, shortness of breath, light-headedness, dizziness, chest pain/pressure.

$\square$ a. Yes, very much

b. Yes, somewhat

$\square$ c. No, has not bothered me

This past year, I have visited the emergency department and/or had unplanned visits with my family doctor with

concerns about my atrial fibrillation:

a. More than once

b. Once

c. Never

Step 2 Determine your results

I have all c's = Green

have 1 or more b's and no a's = Yellow

have 1 or more $a^{\prime} s=$ Red

Green Heart Health The management of your symptoms seems to be good. Keep doing what you're doing.

Yellow Heart Health Changes may need to be made to your medications to provide better control of your symptoms. You should follow up on your next visit or within 2 months with your family doctor.

- Red Heart Health Changes may need to be made to your medications to provide better control of you symptoms. You should ideally follow up with your family doctor within 2 weeks.

Figure 3 Final version, patient-facing tool.

Committee that assesses plain language and literacy level, but input is not received from the patient until after wide-scale dissemination. This approach may result in tools that do not meet patients' needs as effectively.

We found that by engaging end users in the tooldevelopment process we were able to identify potential problems and opportunities in the early stages of development to make our tool more effective. By working in a team composed of a variety of professional perspectives, including specialists, primary care providers, nurses, pharmacists, researchers, usability experts, and designers, we could design a more holistic tool.

There are several limitations to this work that require further research. Although the initial prototype was tested 

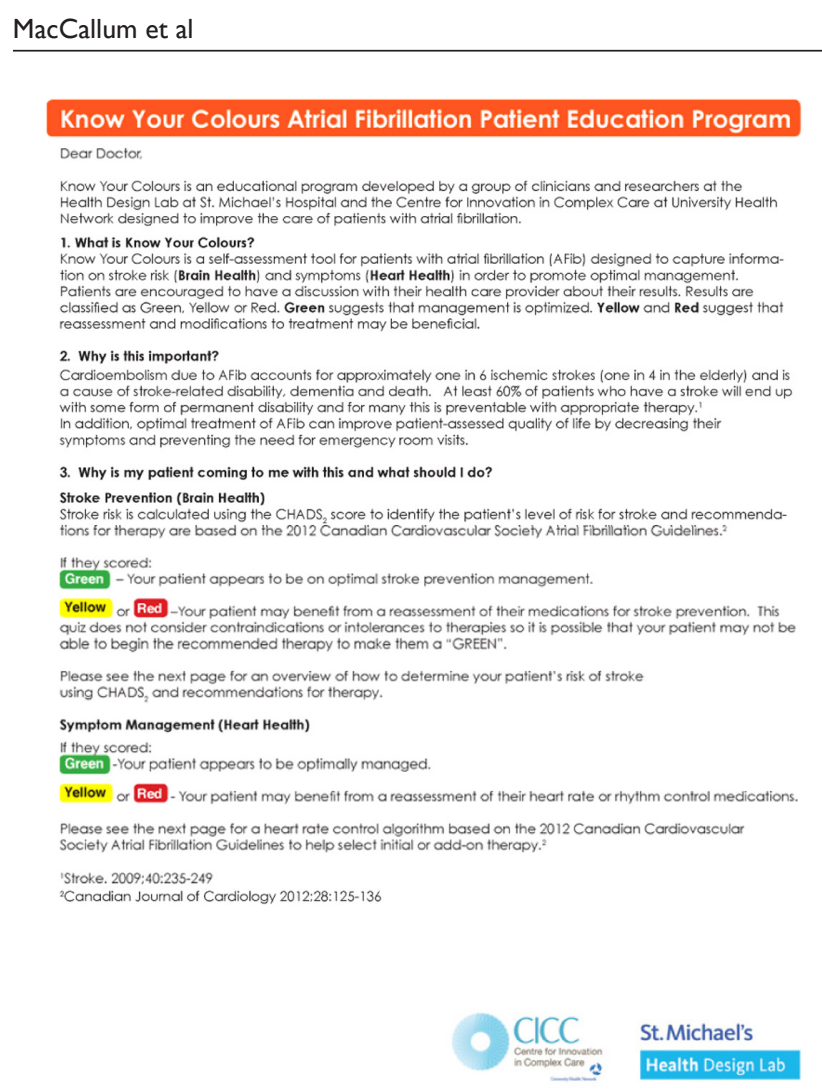

Figure 4 Prescriber-facing tool.

with end users and these findings were used to improve upon the tool, the final version was not tested again. In addition, although we routinely obtained feedback on the provider letter and tool from physicians in our working group, as well as several external family physicians, the feedback was informal and did not follow a standardized script. These limitations will be addressed as part of another study that is currently underway.

For our next phase of research, the tool will be mailed to patients identified with a diagnosis of AF $(n=160)$ in a family practice clinic. The provider letter and tool will also be provided to all the family physicians $(n=13)$ at the clinic. The primary objective is to determine if the 'Know Your Colours' tool improves the proportion of patients receiving guideline-concordant care according to the 2012 CCS AF guidelines. ${ }^{15}$ Secondary objectives include usability testing from both the patients' and the physicians' perspectives and to assess if there is improved documentation in the electronic medical record. Other methods of dissemination are being discussed including having the tool available on a website coupled with a public awareness campaign. However, this will be a future phase of the work.

This work was promising but can still be built upon in many ways. The 'Know Your Colours' project serves as an example of how patient-centered tools can be developed using

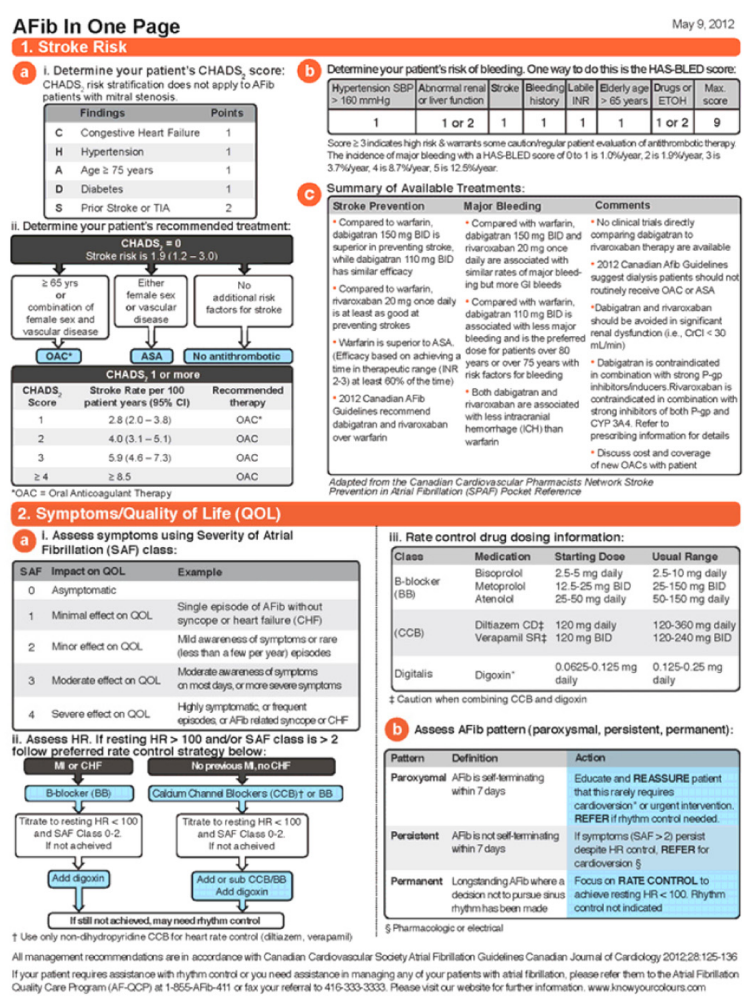

an interdisciplinary collaborative approach and tested using patient input during the development phase.

\section{Conclusion}

The 'Know Your Colours' project resulted in a useful patient tool, largely due to the inter-disciplinary approach taken in its development. By incorporating patient input and human-centered design with the knowledge, experience, and medical expertise of health care providers, we were able to more efficiently create a tool that addressed patients' needs.

\section{Disclosure}

The Atrial Fibrillation Innovation Program project is supported in part by an unrestricted educational grant from Boehringer Ingelheim. The study was carried out independently of the funder. The publication of this study's results was not reviewed by or contingent on the approval or censorship of any affiliated sponsor.

\section{References}

1. Wolf PA, Abbot RD, Kannel WB. Atrial fibrillation: a major contributor to stroke in the elderly. The Framingham Study. Arch Intern Med. 1987;147(9):1561-1564.

2. Gooden JY, Powell BD, Akogyeram CO, Melduni RM. Recent advances in the pharmacological management of atrial fibrillation. Am J Ther. Epub May 17, 2013. 
3. Atzema CL, Austin PC, Miller E, Chong AS, Yun L, Dorian P. A population-based description of atrial fibrillation in the emergency department, 2002 to 2010. Ann Emerg Med. Epub June 26, 2013.

4. Wattigney WA, Mensah GA, Croft JB. Increasing trends in hospitalization for atrial fibrillation in the United States, 1985 through 1999: implications for primary prevention. Circulation. 2003;108(6):711-716.

5. Gladstone DJ, Bui E, Fang J, et al. Potentially preventable strokes in high-risk patients with atrial fibrillation who are not adequately anticoagulated. Stroke. 2009;40(1):235-240.

6. Dorian P, Guerra PG, Kerr CR, et al. Validation of a new simple scale to measure symptoms in atrial fibrillation: the Canadian Cardiovascular Society Severity in Atrial Fibrillation Scale. Circ Arrhythm Electrophysiol. 2009;2(3):218-224.

7. Danelich IM, Reed BN, Hollis IB, Cook AM, Rodgers JE. Clinical update on the management of atrial fibrillation. Pharmacotherapy. 2013;33(4):422-446.

8. Lip GY, Tse HF, Lane DA. Atrial fibrillation. Lancet. 2012;379(9816): 648-661.

9. Improving Chronic Illness Care. The Chronic Care Model [webpage on the Internet]. Available from: http://www.improvingchroniccare.org. Accessed February 25, 2010.

10. Leonard KJ, Wiljer D, Urowitz S. Yes, Virginia, there are system benefits to be gained from providing patients access to their own health information. Healthc Q. 2008;11(4):64-68.
11. Hibbard JH, Mahoney ER, Stock R, Tusler M. Do increases in patient activation result in improved self-management behaviors? Health Serv Res. 2007;42(4):1443-1463.

12. Hibbard JH, Greene J, Tusler M. Improving the outcomes of disease management by tailoring care to the patient's level of activation. $\mathrm{Am} \mathrm{J}$ Manag Care. 2009;15(6):353-360.

13. Becker ER, Roblin DW. Translating primary care practice climate into patient activation: the role of patient trust in physician. Med Care. 2008; 46(8):795-805.

14. Skolasky RL, Mackenzie EJ, Wegener ST, Riley LH III. Patient activation and adherence to physical therapy in persons undergoing spine surgery. Spine (Phila Pa 1976). 2008;33(21):E784-E791.

15. Skanes AC, Healey JS, Cairns JA, et al; Canadian Cardiovascular Society Atrial Fibrillation Guidelines Committee. Focused 2012 update of the Canadian Cardiovascular Society atrial fibrillation guidelines: recommendations for stroke prevention and rate/rhythm control. Can J Cardiol. 2012;28(2):125-136.

16. Unger R, Chandler C. A Project Guide to UX Design: For User Experience Designers in the Field or in the Making. Berkeley (CA): New Riders; 2009. 


\section{Supplementary material}

\section{Usability testing guide}

1. Before we start, can you tell me what you do for a living? (If they are retired capture what they did prior to retiring).

2. Is English your first language?

3. Have you ever heard of atrial fibrillation before?

4. What are your first impressions of this tool?

5. Can you tell me based on what you see what it is for?

6. "Do You Know Your Atrial Fibrillation Colours" is a selfassessment tool that you would receive from a healthcare provider. It would help you and your healthcare provider identify your risk of stroke and if your symptoms are being managed in the best possible way. Do you think you would ever use this? Why/why not?
7. Show me how you would complete this sheet.

8. Heart: Is figuring out your score straightforward?

9. Brain: Is figuring out your score straightforward?

10. Do you think you would complete this and bring it to your family physician, why/why not?

11. Are there any terms used that you found difficult to understand?

12. What are your overall impressions of what you've seen today? Does anything stand out as confusing? Is there anything missing?

13. Do you have any other questions or comments?

\section{Publish your work in this journal}

Patient Preference and Adherence is an international, peer-reviewed, open access journal focusing on the growing importance of patient preference and adherence throughout the therapeutic continuum. Patient satisfaction, acceptability, quality of life, compliance, persistence and their role in developing new therapeutic modalities and compounds to optimize clinical outcomes for existing disease states are major areas of interest. This journal has been accepted for indexing on PubMed Central. The manuscript management system is completely online and includes a very quick and fair peer-review system. Visit http://www.dovepress.com/ testimonials.php to read real quotes from published authors. 